\title{
Chitosan oligosaccharide improves the therapeutic efficacy of sitagliptin for the therapy of Chinese elderly patients with type 2 diabetes mellitus
}

This article was published in the following Dove Press journal:

Therapeutics and Clinical Risk Management

27 June 2017

Number of times this article has been viewed

\author{
Lijie Zhao' \\ Tingli Sun ${ }^{2}$ \\ Lina Wang' \\ 'Department of Geriatrics, \\ ${ }^{2}$ Department of Nephrology, \\ General Hospital of Daqing \\ Oil Field, Daqing, China
}

Correspondence: Lina Wang

Department of Geriatrics, General Hospital of Daqing Oil Field, No 9

Zhongkang Street, Daqing I6331 I, China

Tel +864595805175

Email wanglina5I7@I26.com
Abstract: Sitagliptin improves glycemic control in type 2 diabetes mellitus (T2DM) patients but its side effects are undesirable. Chitosan oligosaccharide (COS) is expected to improve the therapeutic result as a natural product. A total of 200 elderly T2DM patients were evenly assigned into four groups: sitagliptin group (SG), receiving sitagliptin $100 \mathrm{mg}$ /day; COS group (CG), receiving COS $100 \mathrm{mg}$ /day; combination therapy of sitagliptin and COS group (SCG), receiving both sitagliptin and COS $100 \mathrm{mg} /$ day; and placebo group (PG), receiving placebo $100 \mathrm{mg} /$ day. After 42-week therapy, biochemical indices and clinical parameters for the alterations from start points were analyzed. The related molecular mechanism was tested by quantitative real-time polymerase chain reaction (qRT-PCR) and Western blot at cell level. Lower risk of hypoglycemia was found in the SCG group when compared with SG and other groups $(P<0.05)$. More patients from the SCG group than other groups attained hemoglobin A1c $(\mathrm{HbA} 1 \mathrm{c})$ reduction $>2.5 \%(P<0.05)$. Weight reduction of $1.2 \pm 0.9,2.6 \pm 0.8,4.7 \pm 1.3$, and $0.9 \pm 0.6 \mathrm{~kg}$ was observed in the patients from $\mathrm{SG}, \mathrm{CG}, \mathrm{SCG}$, and PG groups, respectively $(P<0.05)$. The combined treatment of COS and sitagliptin presented better therapeutic results by improving insulin sensitivity, lipid profile, adiponectin levels, and glucagon-like peptide 1 and reducing side effects, insulin resistance, $\mathrm{HbAlc}$, body mass index, resistin, tumor necrosis factor (TNF)- $\alpha$, and C-reactive protein (CRP) $(P<0.05)$. qRT-PCR and Western blot analysis also showed that COS treatment reduced the levels of resistin, TNF- $\alpha$, and CRP, and increased the level of adiponectin. The combination of COS and sitagliptin provided better glycemic control with fewer side effects and with more weight reduction in the elderly participants with T2DM.

Keywords: C-reactive protein, glucagon-like peptide 1, chitosan oligosaccharide, sitagliptin, type 2 diabetes mellitus, insulin sensitivity, adiponectin

\section{Introduction}

Type 2 diabetes mellitus (T2DM) is prevalent in the elderly population, has been widely reported, and increases with human aging. ${ }^{1}$ The number of T2DM patients in the elderly population is expected to reach 120 million by $2030 .^{2}$ It has been well known that poor glucose control is associated with elderly T2DM patients. However, glycemic control in the elderly population proposes a big challenge. In this population, the incidences of hypoglycemia increase while hypoglycemia is related to increasing morbidity, ${ }^{3,4}$ which significantly affects the quality of life of patients.

In the therapy of elderly T2DM patients, insulin and oral antidiabetic drugs have occupied a high proportion of adverse event-related drugs. Sitagliptin, an important dipeptidyl peptidase-4 inhibitor, ${ }^{5}$ improves glycemic control, and is often combined 
with metformin ${ }^{6}$ or pioglitazone. ${ }^{7}$ In the study of elderly patients with T2DM, glycemic controls can be achieved by using sitagliptin. ${ }^{8}$

There are some side effects for sitagliptin therapy of T2DM although it has been widely used. T2DM patients using sitagliptin may develop rhinorrhea, cough, dyspnea, and tiredness and these symptoms disappear immediately after the medicine is stopped. ${ }^{9}$ Furthermore, although sitagliptin can lower glucose concentration effectively, its longterm use can cause some adverse effects, such as infections, depression, and cancer. ${ }^{10}$

Chitosan oligosaccharide (COS), as a depolymerized product of chitosan, has received much attention in the biomedical, food, pharmaceutical, and environmental industries because of its biocompatible and biodegradable properties. ${ }^{11} \mathrm{COS}$ has antioxidative, ${ }^{12}$ anti-inflammatory, ${ }^{13}$ and antibacterial bioactivities..$^{14}$ It has the potential to treat age-related dysfunctions including oxidative stress and chronic inflammation. ${ }^{15}$ Catheter-induced infection and healthcare-related infection increase the mortality rate and hospital charges. COS is found to control the incidence of healthcare-associated infection. ${ }^{16}$ A number of publications have been devoted to the antidiabetic effect of COS. For instance, low molecular weight COS has the potential for hyperglycemia management and provides a strong rationale for T2DM prevention via COS. ${ }^{17}$ COS can help control postprandial glucose in subjects with prediabetes. ${ }^{18} \mathrm{COS}$ demonstrates its antidiabetic effect by inhibiting the expression of intestinal $\alpha$-glucosidase, glucose transporters, and peroxisome proliferator-activated receptor $\gamma .{ }^{19}$ More importantly, COS can be widely used as a medicine delivery system with fewer side effects. ${ }^{20}$ Therefore, it is believed that COS may improve the therapeutic results of sitagliptin in the therapy of elderly patients with T2DM.

\section{Methods}

Mass analysis of COS using matrixassisted laser desorption/ionization-timeof-flight (MALDI-TOF)

$\mathrm{COS}$, with a mean molecular weight of $5 \mathrm{kDa}$ and deacetylated degree $>90 \%$, was prepared as per earlier reports. ${ }^{21}$ Briefly, $100 \mathrm{~g}$ shrimp shell was deproteinized in $1 \mathrm{~L} \mathrm{NaOH}$ solution (1 M) for 1 day, and then demineralized in $\mathrm{HCl}(1 \mathrm{M})$ for 1 day. Pigments and lipid were removed by using $95 \%$ ethanol at $70^{\circ} \mathrm{C}$. Chitin was deacetylated in $50 \%(\mathrm{w} / \mathrm{w}) \mathrm{NaOH}$ solution until $90 \%$ degree of deacetylation was obtained. Low-level degree of polymerization (DP) of COS was prepared according to a previous report with some modification. ${ }^{22}$ Chitosan (100 mL, 1\% [v/w], pH 6.0) was added with $20 \mu \mathrm{L}$ recombinant chitosanase. After incubation for 30 minutes at $39^{\circ} \mathrm{C}$, hydrolysis reactions were terminated by boiling for 15 minutes, cooling, and centrifugation to remove insoluble chitosan. Samples $(1 \mu \mathrm{L})$ and $2 \mu \mathrm{L}$ 2,5-dihydroxybenzoic acid $(15 \mathrm{mg} / \mathrm{mL})$ were added to $30 \%$ ethanol. Mass spectra were observed on an Agilent 6530 accurate-mass system (Agilent Technologies, Santa Clara, CA, USA). The spectrum was examined via external calibration.

\section{Participants}

All procedures were confirmed and approved by the Ethics Committee of General Hospital of Daqing Oil Field (approval no DQ201305X26) on April 6, 2013. All steps were performed according to the Declaration of Helsinki. ${ }^{23}$ From May 2013 to August in 2014, 416 elderly T2DM patients ( $\geq 60$ years) were recruited.

\section{Inclusion criteria}

Patients were included if 1) they had T2DM for $>5$ years; 2) their hemoglobin A1c (HbA1c) $<10.5 \%$; 3$)$ their body mass index (BMI) $>25$ and $<39 \mathrm{~kg} / \mathrm{m}^{2} ; 4$ ) they had stable weight for $>3$ months before the present experiment; 5) they had no other serious diseases; 6 ) their fasting plasma glucose (FPG) was $>130$ or $<240 \mathrm{mg} / \mathrm{dL}$.

\section{Exclusion criteria}

Patients were excluded from the study if they 1) had T1DM; 2) had renal function impairment; 3) had an FPG $>270 \mathrm{mg} / \mathrm{dL}$; 4) achieved weight loss by using medicines within 3 months before the present experiment; 5) had a family history of T2DM; and 6) if it was hard to chat with them.

\section{Grouping}

After selection using the above criteria, 200 elderly T2DM patients $\geq 60$ years of age were finally selected and randomized to consume sitagliptin $100 \mathrm{mg}$ /day (sitagliptin group [SG]), COS $100 \mathrm{mg} /$ day (COS group [CG]), the combination of sitagliptin $100 \mathrm{mg} /$ day and COS $100 \mathrm{mg}$ /day (sitagliptin and COS group [SCG]), or placebo $100 \mathrm{mg} /$ day (placebo group [PG]), respectively. HbA1c data from all patients were recorded at the start of the study and all subjects were randomized and subjected to double-blind studies. All patients provided written informed consent to participate in the experiment.

\section{Clinical characterization}

Patients' BMI was calculated by dividing weight $(\mathrm{kg})$ by the square of height $\left(\mathrm{m}^{2}\right)$. Other elements, such as weight, age, 
gender, lifestyle, and hypertension, were also noted in the present experiment.

\section{Biochemical analysis}

Capillary whole blood glucose levels were measured in all patients. Those with a capillary whole blood glucose level $>6.1 \mathrm{mM}$ were a higher risk of diabetes. ${ }^{24}$ The concentration of glucose and the level of HbAlc were tested after 2 hours following glucose intake. Serum glucose levels, basal blood glucose (BG), and fasting blood glucose (FBG) were measured by an EMP Medical-Chemistry Analyzer (Shenzhen Emperor Electronic Technology Co, Ltd, Shenzhen, China). HbAlc levels were measured by using affinity chromatography (GE Healthcare [Shanghai] Co, Ltd, Shanghai, China). Levels of total cholesterol (TC), high-density lipoprotein-cholesterol (HDL-c) and low-density lipoprotein-cholesterol (LDL-c) were examined by using an assay kit (cat no ab65390; Abcam, Shanghai, China). Triglyceride (TG) levels were determined by using a Triglyceride Quantification Assay Kit (cat no ab65336; Abcam). Serum insulin was tested by Abcam's Insulin Simple Step Kit (cat no ab200011). Serum basal insulin (BINS) and fasting insulin (FINS) were examined by a radioimmunoassay kit (Shanghai Traditional Medicine University, Shanghai, China). Insulin resistance (HOMA-IR) indexes were calculated as HOMA-IR $=\mathrm{FBG} \times \mathrm{FINS} / 22.5$. Insulin secretory (HOMA-IS) activity was measured as HOMA-IS $=20 \times$ FINS/(FBG-3.5). HOMA of $\beta$-cell activity (HOMA-B) was calculated as HOMA-B $=20 \times \mathrm{BINS} /(\mathrm{BG}-3.5)$.

\section{Enzyme-linked immunosorbent assay (ELISA) tests}

The serum concentrations of target proteins were measured by using ELISA kits. Human C-reactive protein (CRP; cat no ab99995), human tumor necrosis factor- $\alpha$ (TNF- $\alpha$; cat no ab46087), human adiponectin (cat no ab99968), human resistin (cat no ab100634), and human glucagon-like peptide 1 (GLP-1; cat no ab184857) were purchased from Abcam and analyses were performed.

\section{Analysis of side effects at endpoints}

The endpoint analysis included changes of $\mathrm{HbAlc}, \mathrm{FPG}$, and BMI from baseline. Side effects (fatigue, ${ }^{9}$ cough, ${ }^{9}$ headache, ${ }^{25}$ hypoglycemia, ${ }^{26}$ loss of consciousness, ${ }^{26}$ constipation, ${ }^{27}$ nausea, ${ }^{27}$ vomiting, ${ }^{27}$ and diarrhea ${ }^{28}$ ) were measured. All patients had no such side effects before this study. Side effect scales were evaluated based on the frequency of experiences on a 5-point scale: never, seldom, sometimes, very often, and permanently.

\section{Cell culture}

Adipocytes 3T3-L1 and 3T3-F442A were obtained from Cell Bank of Shanghai Institute of Cell Biology, Chinese Academy of Sciences (Shanghai, China). All cells were cultured with Dulbecco's Modified Eagle's Medium (DMEM) in a $37^{\circ} \mathrm{C}$ incubator with $5 \% \mathrm{CO}_{2}$. $3 \mathrm{~T} 3$-L1 and 3T3-F442A cells were treated with $1 \mathrm{mg} / \mathrm{L}$ sitagliptin (SG), $1 \mathrm{mg} / \mathrm{L}$ sitagliptin and $1 \mathrm{mg} / \mathrm{L}$ COS (SCG), and cultured in DMEM for 72 hours.

\section{Quantitative real-time polymerase chain reaction ( $q R T-P C R$ )}

All cells were collected and RNA was isolated with an RNA purification kit (cat no KIT0312-I; Fisher Scientific, Waltham, MA, USA). The primers were designed as follows: CRP forward primer, 5'-ctgtcctcgacceggggtac-3'; CRP reverse primer, $5^{\prime}$-tgtgtactggagctactgtg- $3^{\prime}(160 \mathrm{bp})$; TNF- $\alpha$ forward primer, $5^{\prime}$-tattatacccagccagcgcc- $3^{\prime}$; TNF- $\alpha$ reverse primer, 5'-agccaggtcagagcaccggc-3' (170 bp); adiponectin forward primer, $5^{\prime}$-ggtgaaaccggagtacccgg- $3^{\prime}$; adiponectin reverse primer, $5^{\prime}$-tggtaaagcgaatgggcatg- $3^{\prime}$ (160 bp); resistin forward primer, $5^{\prime}$-ctgtgctccatggaagaagc- $3^{\prime}$; resistin reverse primer, $5^{\prime}$-ggtgacggcgaagcctcggg-3' (130 bp); and GAPDH forward primer, 5'-gtggtggctgtgaatgatcc-3'; GAPDH reverse primer, $5^{\prime}$-accacgtaggggctcccgac- $3^{\prime}$ (200 bp). PCR was performed using the following protocol: denaturation at $94^{\circ} \mathrm{C}$ for 20 seconds, annealing at $55^{\circ} \mathrm{C}$ for 20 seconds, and extension at $72^{\circ} \mathrm{C}$ for 20 seconds, 40 cycles. PCR products were compared between SG and SCG.

\section{Western blot analysis}

Cell lines 3T3-L1 and 3T3-F442A were disrupted by hypotonic lysis in sterile water. Human CRP antibody AF1707, human TNF- $\alpha$ antibody MAB210-100, human adiponectin/Acrp30 antibody (AF1065), human resistin antibody MAB13591-100, and human GAPDH antibody MAB5718 were from R\&D Systems (Minneapolis, MN, USA).

\section{Statistical analysis}

The COS effect was evaluated at a two-sided $P<0.05$. Fisher's exact test was performed to compare categorical variables, including side effects events and incidences of hypoglycemia. Predefined analysis was performed to investigate variations in $\mathrm{HbAlc}$ and FBG. All data were presented as mean \pm standard deviation and analyzed by SPSS statistics 20.0 (IBM Corporation, Armonk, NY, USA). A $P$-value $<0.05$ was considered significant. 


\section{Results}

\section{COS analysis}

MALDI-TOF mass spectrometry was used to analyze COS and the results showed that the main products for DP were DP3, 4, and 5 when potassium adduct ions were calculated in MALDI-TOF (Figure 1).

\section{Baseline characters of all participants}

After selection, 200 T2DM elderly patients were selected. Fifty participants each in 4 groups received sitagliptin, COS, the combination of sitagliptin and COS, and placebo, respectively (Table 1). The mean ages were 69.1 $\pm 8.4,67.8 \pm 7.5$, $68.9 \pm 8.8$, and $68.5 \pm 8.0$ years in SG, CG, SCG, and PG groups, respectively. There was no statistical significance of differences for baseline characteristics among the four groups $(P>0.05)$.

\section{More weight loss in SCG group}

Table 2 showed that the combination therapy was superior than only sitagliptin and other groups $(P<0.05)$. Subjects in the SCG group had more weight loss $(P<0.01)$, with mean weight decreases of $1.2 \pm 0.9,2.6 \pm 0.8,4.7 \pm 1.3$, and $0.9 \pm 0.6 \mathrm{~kg}$ in $\mathrm{SG}, \mathrm{CG}, \mathrm{SCG}$, and $\mathrm{PG}$ groups, respectively (Table 2). Similarly, patients demonstrated more BMI loss in the SCG group than in SG and other groups $(P<0.05)$ (Figure 2A). For alterations in HbA1c after the 42-week trial, decreases occurred in the SCG group than in SG and other groups. There were significant differences for $\mathrm{HbA} 1 \mathrm{c}$ levels between SCG and SG or other groups after 12-week therapy (Figure 2B, $P<0.05$ ).

\section{Glucose values in SCG compared to SG group}

As Table 1 shows, at 42-week trial, all subjects from the SCG group had lower mean glucose values than the ones from SG or other groups before breakfast and 2 hours post-breakfast $(P<0.05)$. The findings imply that COS decreases the glucose values before breakfast and 2 hours post-breakfast.

\section{Analysis of fasting c peptide (FCP) and 2-hour postprandial c peptide (PCP)}

Results showed that there was no significant change for FCP and 2-hour PCP in the participants from SG to SCG groups $(P>0.05)$ (Table 2). The findings imply that COS cannot effect FCP and PCP.

\section{Changes for resistin, CRP, TNF- $\alpha$, and adiponectin}

The levels of resistin, CRP, TNF- $\alpha$, and insulin resistance were lower in the SCG group than in SG and other groups $(P<0.05)$ (Table 2). Resistin is an important marker for diabetes. It increases in fat persons and anti-resistin therapy reduces blood sugar and increases insulin in animal models. Combined treatment resulted in a higher reduction in resistin concentration from the SCG group than from SG and other groups $(P<0.05)$. There were significant differences

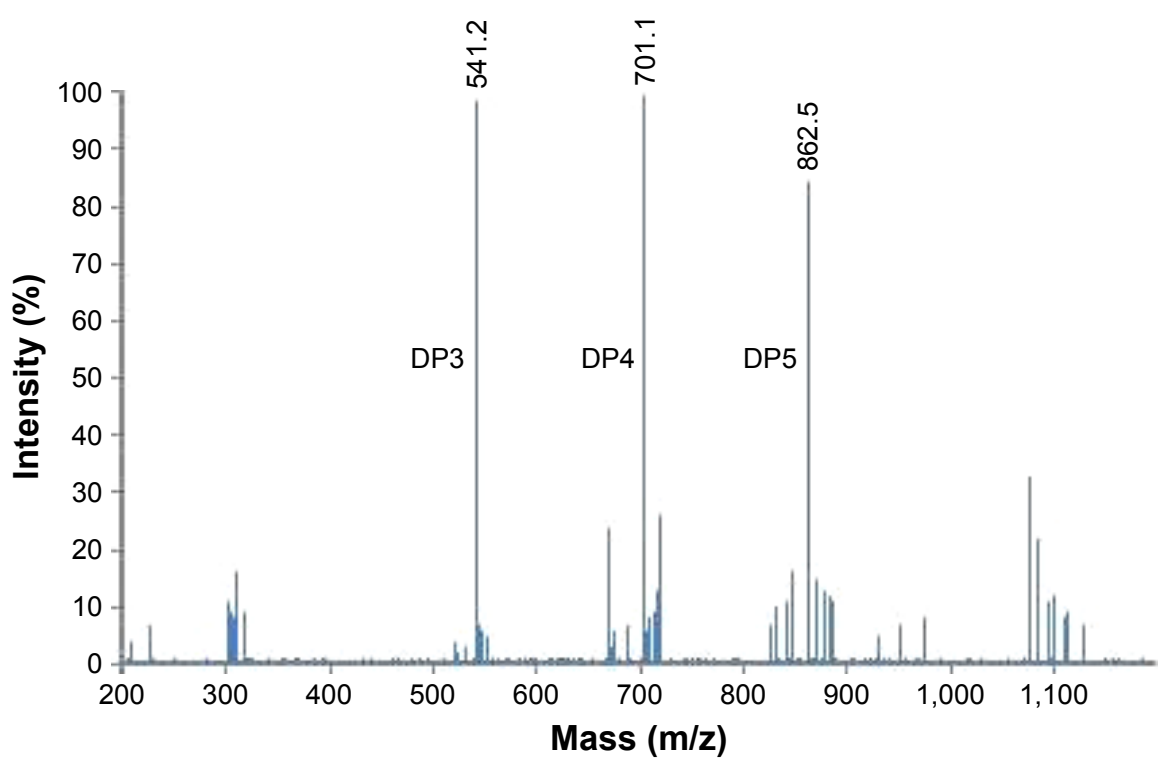

Figure I MALDI-TOF MS analysis of COS.

Note: The main products for DP were DP3, DP4, and DP5 when potassium adduct ions were calculated in MALDI-TOF.

Abbreviations: MALDI-TOF, matrix-assisted laser desorption/ionization-time-of-flight; COS, chitosan oligosaccharide; DP, degree of polymerization; MS, mass spectrometry. 
Table I Baseline characteristics

\begin{tabular}{|c|c|c|c|c|c|}
\hline Characteristics of patients & SG $(n=50)$ & CG $(n=50)$ & $\operatorname{SCG}(n=50)$ & $P G(n=50)$ & $P$-value \\
\hline Age (years) & $69.1 \pm 8.4$ & $67.8 \pm 7.5$ & $68.9 \pm 8.8$ & $68.5 \pm 8.0$ & 0.246 \\
\hline Gender, male, n (\%) & $29(58)$ & $31(62)$ & $30(60)$ & $32(64)$ & 0.683 \\
\hline \multicolumn{6}{|l|}{ Race, n (\%) } \\
\hline Han zhu & $44(88)$ & $43(86)$ & $44(88)$ & $43(86)$ & 0.766 \\
\hline Manchu & $4(8)$ & $5(10)$ & $4(8)$ & $5(10)$ & 0.727 \\
\hline Mongolians & I (2) & $I(2)$ & I (2) & $\mathrm{I}(2)$ & 1.000 \\
\hline Tibetans & I (2) & I (2) & I (2) & I (2) & 1.000 \\
\hline Weight (kg) & $85.6 \pm 16.4$ & $84.7 \pm 14.6$ & $86.7 \pm 15.8$ & $86.1 \pm 15.0$ & 0.145 \\
\hline BMI $\left(\mathrm{kg} / \mathrm{m}^{2}\right)$ & $28.2 \pm 2.9$ & $27.8 \pm 2.6$ & $28.5 \pm 2.7$ & $28.9 \pm 2.4$ & 0.532 \\
\hline Hemoglobin Alc (\%) & $7.6 \pm 0.9$ & $7.9 \pm 0.9$ & $7.5 \pm 0.8$ & $7.6 \pm 0.7$ & 0.107 \\
\hline Duration of diabetes (years) & $5.8 \pm 4.6$ & $5.5 \pm 4.2$ & $5.6 \pm 4.9$ & $5.7 \pm 4.2$ & 0.642 \\
\hline \multicolumn{6}{|l|}{ HR (beats/minute) } \\
\hline 24-hour & $76.8 \pm 14.2$ & $78.4 \pm 14.0$ & $77.4 \pm 15.1$ & $76.4 \pm 14.6$ & 0.728 \\
\hline Daytime & $81.2 \pm 12.3$ & $80.2 \pm 11.5$ & $80.8 \pm 13.5$ & $80.4 \pm 12.1$ & 0.859 \\
\hline Nighttime & $69.4 \pm 8.6$ & $67.6 \pm 9.0$ & $68.9 \pm 9.5$ & $66.5 \pm 8.4$ & 0.678 \\
\hline \multicolumn{6}{|l|}{ SBP (mmHg) } \\
\hline 24-hour & $14 \mid .7 \pm 12.6$ & $|30.6 \pm| \mid .2$ & $139.5 \pm 11.9$ & $134.5 \pm 10.3$ & 0.554 \\
\hline Daytime & $|5| .4 \pm 13.7$ & $153.2 \pm 13.2$ & $150.6 \pm 12.8$ & $147.6 \pm 1 \mid .9$ & 0.762 \\
\hline Nighttime & $|40.8 \pm| 4.2$ & $140.5 \pm 13.3$ & $142.4 \pm 13.6$ & $|45.5 \pm| \mid .8$ & 0.331 \\
\hline \multicolumn{6}{|l|}{$\mathrm{DBP}(\mathrm{mmHg})$} \\
\hline 24-hour & $85.6 \pm 8.2$ & $86.6 \pm 7.5$ & $86.0 \pm 7.3$ & $86.7 \pm 7.1$ & 0.426 \\
\hline Daytime & $87.5 \pm 8.0$ & $86.2 \pm 7.4$ & $89.1 \pm 7.8$ & $85.9 \pm 7.2$ & 0.584 \\
\hline Nighttime & $79.4 \pm 8.2$ & $77.4 \pm 6.9$ & $78.9 \pm 6.6$ & $78.0 \pm 6.1$ & 0.252 \\
\hline \multicolumn{6}{|c|}{ Failing with single-drug treatment, $n$} \\
\hline $\mathrm{BIA}$ & 17 & 19 & 17 & 19 & 0.677 \\
\hline Exenatide & 15 & 16 & 15 & 16 & 0.829 \\
\hline MET & 14 & 13 & 13 & 14 & 0.822 \\
\hline
\end{tabular}

Notes: Chi-square test and $t$-test were performed to compare the variance between two groups. There are significant statistic differences at $P<0.05$. Data presented as mean \pm SD unless indicated otherwise.

Abbreviations: SCG, sitagliptin and chitosan oligosaccharide group; CG, chitosan oligosaccharide group; SG, sitagliptin group; PG, placebo group; BMI, body mass index; HR, heart rate; SBP, systolic blood pressure; DBP, diastolic blood pressure; BIA, biphasic insulin aspart; MET, metformin.

Table 2 Parameter changes after 42-week trial

\begin{tabular}{|c|c|c|c|c|c|c|}
\hline Parameters & $S G(N=50)$ & $C G(N=50)$ & SCG $(N=50)$ & $P G(N=50)$ & $t$-value & $P$-value \\
\hline Weight (kg) & $84.4 \pm 15.7$ & $82.1 \pm 14.9$ & $82.0 \pm 17.6$ & $85.2 \pm 14.0$ & 1.79 & 0.015 \\
\hline BMI $\left(\mathrm{kg} / \mathrm{m}^{2}\right)$ & $26.4 \pm 1.2$ & $26.8 \pm 1.4$ & $24.5 \pm 1.5$ & $28.6 \pm 1.9$ & 1.23 & 0.027 \\
\hline FBG (mmol/L) & $7.9 \pm 1.1$ & $8.0 \pm 1.0$ & $7.3 \pm 1.0$ & $8.6 \pm 1.3$ & 2.01 & 0.018 \\
\hline $2 \mathrm{hPG}(\mathrm{mmol} / \mathrm{L})$ & $12.4 \pm 1.5$ & $13.5 \pm 1.9$ & $10.4 \pm 1.7$ & $14.4 \pm 1.8$ & 0.85 & 0.022 \\
\hline HbAlc (\%) & $7.5 \pm 0.9$ & $7.0 \pm 0.8$ & $6.8 \pm 0.9$ & $8.7 \pm 0.8$ & 0.74 & 0.037 \\
\hline TG (mmol/L) & $2.2 \pm 1.3$ & $2.4 \pm 1.1$ & $1.8 \pm 1.0$ & $2.6 \pm 1.3$ & 0.75 & 0.030 \\
\hline $\mathrm{TC}(\mathrm{mmol} / \mathrm{L})$ & $5.2 \pm 2.3$ & $5.5 \pm 1.8$ & $4.5 \pm 1.6$ & $6.0 \pm 1.9$ & 0.63 & 0.021 \\
\hline $\mathrm{HDL}(\mathrm{mmol} / \mathrm{L})$ & $1.5 \pm 0.8$ & $1.4 \pm 0.6$ & $1.6 \pm 0.5$ & $1.4 \pm 0.3$ & 0.23 & 0.143 \\
\hline LDL (mmol/L) & $3.9 \pm 1.7$ & $3.6 \pm 1.1$ & $2.8 \pm 1.0$ & $4.5 \pm 1.2$ & 0.81 & 0.042 \\
\hline FINS (pmol/L) & $124.6 \pm 45.7$ & $127.6 \pm 39.3$ & $119.4 \pm 37.9$ & $138.5 \pm 36.4$ & 0.97 & 0.025 \\
\hline HOMA-IR & $5.8 \pm 2.4$ & $6.0 \pm 2.4$ & $4.5 \pm 2.5$ & $6.3 \pm 2.9$ & 1.08 & 0.031 \\
\hline HOMA-IS & $80.3 \pm 54.2$ & $78.3 \pm 50.9$ & $91.6 \pm 43.8$ & $70.3 \pm 52.3$ & 2.97 & 0.016 \\
\hline Fasting c peptide (nmol/L) & $1.2 \pm 0.5$ & $1.1 \pm 0.4$ & $1.1 \pm 0.3$ & $1.1 \pm 0.4$ & 0.11 & 0.092 \\
\hline 2-hour postprandial c peptide (nmol/L) & $2.57 \pm 1.1$ & $2.84 \pm 1.2$ & $2.73 \pm 1.2$ & $2.86 \pm 1.3$ & 0.44 & 0.074 \\
\hline Resistin (ng/mL) & $|1.34 \pm 0.5|$ & $13.18 \pm 0.44$ & $7.15 \pm 0.36$ & $16.22 \pm 0.38$ & 3.21 & 0.001 \\
\hline Adiponectin (pg/mL) & $158.5 \pm 7.6$ & $142.5 \pm 8.5$ & $172.1 \pm 10.8$ & $123.4 \pm 7.6$ & 1.22 & 0.044 \\
\hline C-reactive protein (mg/L) & $5.1 \pm 0.6$ & $5.4 \pm 0.5$ & $4.2 \pm 0.4$ & $6.2 \pm 0.5$ & 3.64 & 0.007 \\
\hline TNF- $\alpha(\mathrm{pg} / \mathrm{mL})$ & $312.7 \pm 19.9$ & $326.4 \pm 17.3$ & $280.1 \pm 16.4$ & $345.6 \pm 18.2$ & 3.89 & 0.005 \\
\hline
\end{tabular}

Notes: ANOVA was performed to compare the variance among four groups. Data presented as mean \pm SD. There are significant statistic differences at $P<0.05$.

Abbreviations: SCG, sitagliptin and chitosan oligosaccharide group; CG, chitosan oligosaccharide group; SG, sitagliptin group; PG, placebo group; ANOVA, analysis of variance; SD, standard deviation; BMI, body mass index; FBG, fasting blood glucose; HbAlc, hemoglobin Alc; TG, triglyceride; TC, total cholesterol; LDL, low-density lipoprotein; HDL, high-density lipoprotein; FINS, fasting insulin; HOMA-IR, insulin resistance index; HOMA-IS, insulin secretory activity; TNF, tumor necrosis factor; 2hPG, two-hour plasma glucose. 


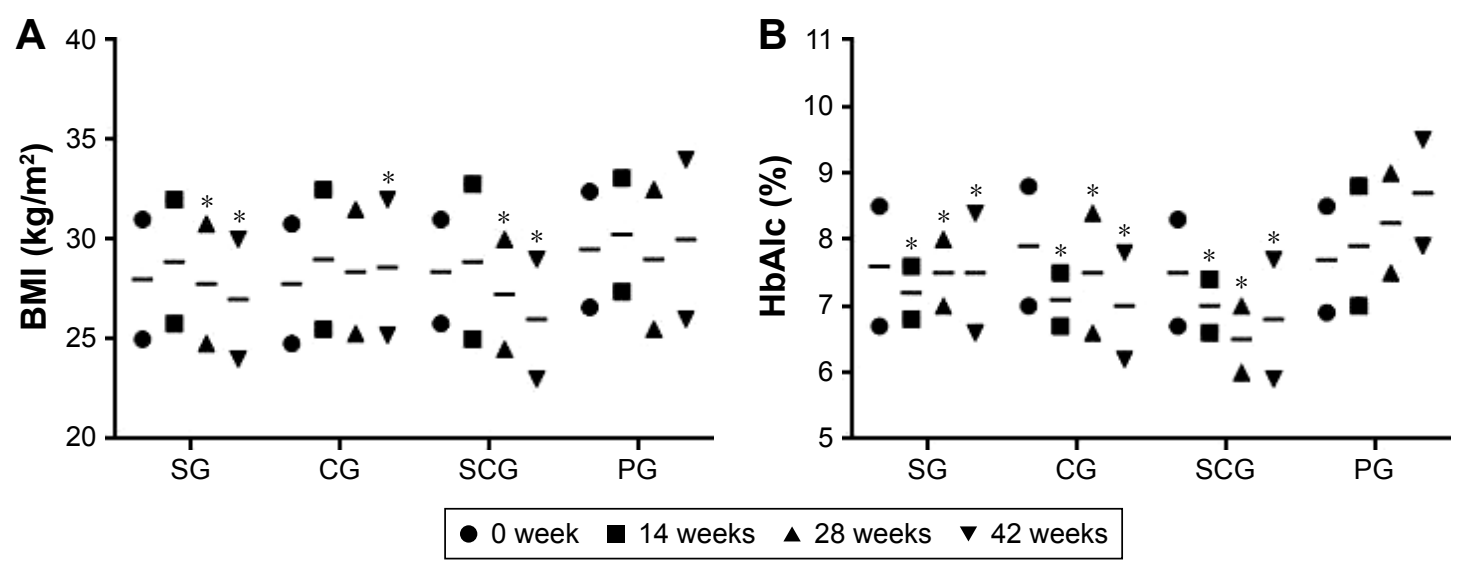

Figure 2 Changes of mean values of (A) BMI and (B) HbAlc (\%) between SCG and SG T2DM patients in a 42-week follow-up. Note: $* P<0.05$ versus PG.

Abbreviations: BMI, body mass index; HbAlc, hemoglobin AI c; SCG, sitagliptin and chitosan oligosaccharide group; CG, chitosan oligosaccharide group; SG, sitagliptin group; T2DM, type 2 diabetes mellitus; PG, placebo group.

for resistin concentration among the four groups since the 24th week (Figure 3A, $P<0.05$ ).

CRP is associated with inflammation and an important biomarker for the development of diabetes. ${ }^{29}$ In this study, combined treatment resulted in a higher reduction in the CRP concentration in SCG than in SG and other groups
$(P<0.05)$. There were significant differences for CRP levels between SCG and SG and/or other groups since the 24th week (Figure 3B, $P<0.05$ ).

TNF- $\alpha$ is an inflammatory cytokine and plays a critical role in insulin resistance. It is found to be at a higher level in lipid tissue. ${ }^{30}$ Combined treatment resulted in a greater
A

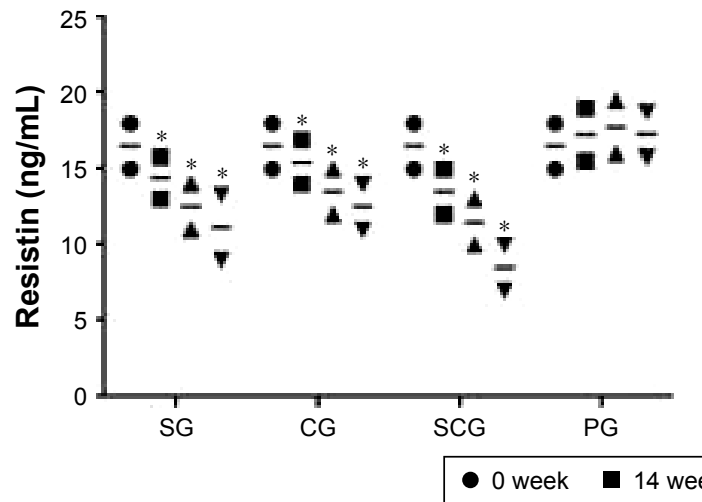

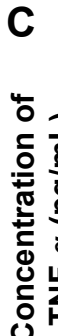

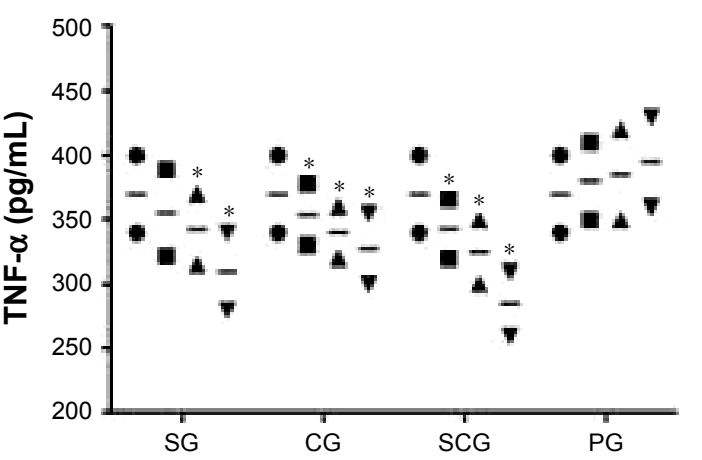

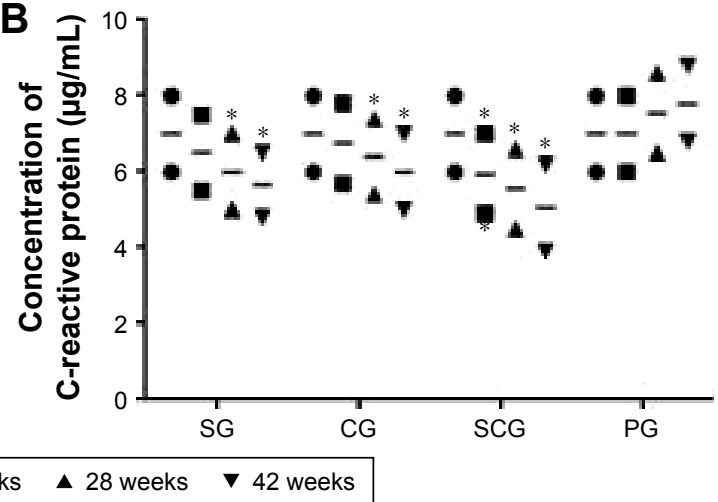

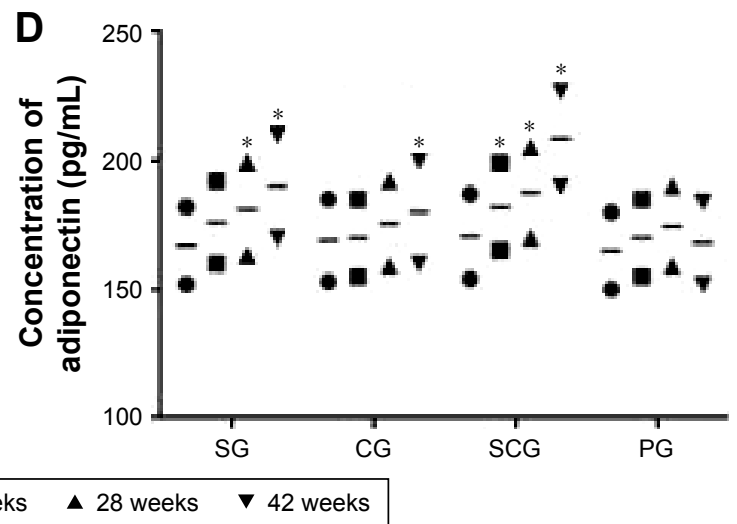

Figure 3 Changes of mean concentrations of $(\mathbf{A})$ resistin $(\mathrm{ng} / \mathrm{mL}),(\mathbf{B})$ C-reactive protein $(\mathrm{mg} / \mathrm{L})$, (C) TNF- $\alpha$ (pg/mL), and (D) adiponectin (pg/mL) between SCG and SG groups in a 42-week follow-up.

Note: ${ }^{* P}<0.05$ versus PG.

Abbreviations: SCG, sitagliptin and chitosan oligosaccharide group; CG, chitosan oligosaccharide group; SG, sitagliptin group; PG, placebo group; TNF, tumor necrosis factor. 
reduction of TNF- $\alpha$ in SCG than in SG and other groups $(P<0.05)$. There were significant differences for TNF- $\alpha$ between SCG and SG and/or other groups at 24th week (Figure $3 \mathrm{C}, P<0.05$ ).

Insulin sensitivity was significantly increased in SG and SCG groups $(P<0.05)$. Adiponectin improves insulin sensitization and anti-inflammation and the lower expressed protein increases the resistance of insulin in fat and diabetic persons. ${ }^{31}$ The levels of adiponectin are lower in T2DM patients than in healthy participants. ${ }^{32}$ The combined method resulted in a higher improvement of adiponectin concentration in SCG than in SG and other groups $(P<0.05)$. Significant differences were found between SCG and SG and other groups since the 24 th week (Figure $3 \mathrm{D}, P<0.05$ ).

\section{Serum concentration of GLP-I}

Figure 4 shows that there is no statistical significance of differences for serum concentration of GLP-1 among the four groups $(P>0.05)$. Comparatively, sitagliptin and/or COS reduced the serum concentration of GLP-1 markedly $(P<0.05)$. Furthermore, the combination of sitagliptin and COS reduced the serum concentration of GLP-1 more than the other groups $(P<0.05)$.

\section{Changes of lipid profile}

Lipid profile is an important parameter for health. As Table 1 showed, TG, TC, and LDL was decreased in HDL was increased in $\mathrm{SG}, \mathrm{CG}$ and $\mathrm{SCG}$ groups $(P<0.05)$. Comparatively, higher decreases in the levels of TG, TC, and LDL were found in the SCG than SG group $(P<0.05)$ (Table 2$)$. The present finding suggests that combined treatment reduced

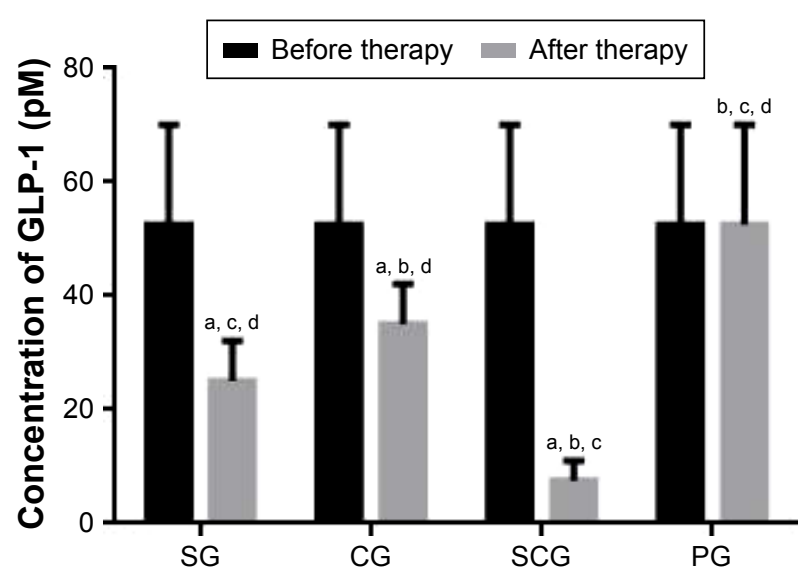

Figure 4 Serum concentration of GLP-I in different groups.

Notes: Data presented as mean \pm SD. a $P<0.05$ versus $P G,{ }^{b} P<0.05$ versus $S G$, $c P<0.05$ versus $C G$, and $d P<0.05$ versus $S C G$.

Abbreviations: GLP-I, glucagon-like peptide I; SD, standard deviation; SCG, sitagliptin and chitosan oligosaccharide group; CG, chitosan oligosaccharide group; SG, sitagliptin group; PG, placebo group. the levels of TG, TC, and LDL more in SCG than in the SG group $(P<0.05)$. COS improves the lipid profiles of elderly T2DM patients. In PG, there was no significant change for lipid profiles $(P>0.05)$.

\section{Combination therapy improves HOMA-IS and HOMA-IR}

The participants in SCG group showed improved $\beta$-cell function. HOMA-IS indexes were enhanced from $69.1 \pm 29.8$ (baseline) to $91.6 \pm 43.8$ in the SCG group, from $68.4 \pm 37.4$ (baseline) to $80.3 \pm 54.2$ in the $\mathrm{SG}$ group $(P<0.05)$, from $69.7 \pm 38.6$ (baseline) to $78.3 \pm 50.9$ in the $\mathrm{CG}$ group $(P<0.05)$, and from $68.8 \pm 32.7$ (baseline) to $70.3 \pm 52.3$ in the PG group $(P>0.05)$ after the $42-w e e k$ trial. Conversely, Table 1 shows that the HOMA-IR indexes were reduced from $6.6 \pm 3.5$ to $4.5 \pm 2.5$ in the SCG group, from $6.3 \pm 3.2$ (baseline) to $5.8 \pm 2.4$ in the SG group $(P<0.05)$, from 6.4 \pm 2.8 (baseline) to 6.0 \pm 2.4 in the CG group $(P>0.05)$, and from $6.5 \pm 3.0$ (baseline) to $6.3 \pm 2.9$ in the PG group $(P>0.05)$ after the 42 -week trial. Combined treatment showed a better therapeutic result for $\beta$-cell function by affecting the sensitivity and resistance of insulin.

\section{Experiences of side effects}

The side effect of sitagliptin was assessed according to the scales in Table 3. Patients experienced fatigue, cough, headache, hypoglycemia, loss of consciousness, constipation, nausea, vomiting, and diarrhea as reported in their interviews. Table 3 shows that the incidences of side effects were higher in the SG group than in SCG and other groups. COS reduces these side effects caused by sitagliptin.

\section{qRT-PCR analysis}

qRT-PCR analysis showed that the relative mRNA level of resistin was lower in SCG than SG after 1-day culture $(P<0.05$, Figure 5A). Comparatively, the relative mRNA level of CRP was lower in SCG than SG and other groups after 2-day culture $(P<0.05$, Figure 5B). Relative mRNA level of TNF- $\alpha$ was lower in SCG than SG and other groups after 1-day culture ( $P<0.05$, Figure $5 \mathrm{C})$. In contrast, the relative mRNA level of adiponectin was higher in SCG than SG and other groups after 1 -day culture $(P<0.05$, Figure 5D).

\section{Western blot analysis}

Western blot analysis showed results similar to the qRT-PCR analysis. Relative protein level of resistin was lower in SCG than in SG and other groups after 1-day culture $(P<0.05$, Figure 6A). Comparatively, the relative protein level of 
Table 3 Side effects after 42-week trial

\begin{tabular}{|c|c|c|c|c|c|}
\hline & $\begin{array}{l}\text { Never } \\
\mathrm{n}(\%)\end{array}$ & $\begin{array}{l}\text { Rarely } \\
\text { n (\%) }\end{array}$ & $\begin{array}{l}\text { Sometimes } \\
\text { n (\%) }\end{array}$ & $\begin{array}{l}\text { Very often } \\
n(\%)\end{array}$ & $\begin{array}{l}\text { Always } \\
\text { n (\%) }\end{array}$ \\
\hline \multicolumn{6}{|l|}{ Fatigue } \\
\hline SG & $8(16)$ & $12(24)$ & $14(28)$ & $16(32)$ & $0(0)$ \\
\hline CG & $24(48)$ & $18(36)$ & $5(10)$ & $3(6)$ & $0(0)$ \\
\hline SCG & $10(20)$ & $16(32)$ & $15(30)$ & $8(16)$ & I (2) \\
\hline PG & $20(40)$ & $16(32)$ & $10(20)$ & $4(8)$ & $0(0)$ \\
\hline \multicolumn{6}{|l|}{ Cough } \\
\hline SG & $20(40)$ & $10(20)$ & $15(30)$ & $5(10)$ & $0(0)$ \\
\hline CG & $35(70)$ & $10(20)$ & $4(8)$ & I (2) & $0(0)$ \\
\hline SCG & $25(50)$ & $12(24)$ & II (22) & $2(4)$ & $0(0)$ \\
\hline PG & $30(60)$ & $12(24)$ & $6(12)$ & $2(4)$ & $0(0)$ \\
\hline \multicolumn{6}{|c|}{ Headache } \\
\hline SG & $16(32)$ & $8(16)$ & $20(40)$ & $4(8)$ & $2(4)$ \\
\hline CG & $27(54)$ & $17(34)$ & $5(10)$ & I (2) & $2(4)$ \\
\hline SCG & $19(38)$ & $10(20)$ & $15(30)$ & $4(8)$ & $2(4)$ \\
\hline PG & $25(50)$ & $15(30)$ & $7(14)$ & $2(4)$ & $2(4)$ \\
\hline \multicolumn{6}{|c|}{ Hypoglycemia } \\
\hline SG & $22(44)$ & $10(20)$ & $9(18)$ & $6(12)$ & $3(6)$ \\
\hline CG & $30(60)$ & $14(28)$ & $3(6)$ & $2(4)$ & I (2) \\
\hline SCG & $26(52)$ & $12(24)$ & $9(18)$ & $2(4)$ & I (2) \\
\hline PG & $31(62)$ & $15(30)$ & I (2) & $2(4)$ & I (2) \\
\hline \multicolumn{6}{|c|}{ Loss of consciousness } \\
\hline SG & $29(58)$ & $10(20)$ & II (22) & $0(0)$ & $0(0)$ \\
\hline CG & $33(66)$ & $12(24)$ & $5(10)$ & $0(0)$ & $0(0)$ \\
\hline SCG & $34(68)$ & $10(20)$ & $6(12)$ & $0(0)$ & $0(0)$ \\
\hline PG & $36(72)$ & $12(24)$ & $2(4)$ & $0(0)$ & $0(0)$ \\
\hline \multicolumn{6}{|c|}{ Constipation } \\
\hline SG & $16(32)$ & $12(24)$ & $10(20)$ & $9(18)$ & $2(4)$ \\
\hline CG & $20(40)$ & $16(32)$ & $10(20)$ & $4(8)$ & I (2) \\
\hline SCG & $18(36)$ & $15(30)$ & $10(20)$ & $5(10)$ & $2(4)$ \\
\hline PG & $19(38)$ & $17(34)$ & $12(24)$ & I (2) & I (2) \\
\hline \multicolumn{6}{|l|}{ Nausea } \\
\hline SG & $25(50)$ & $15(30)$ & $6(12)$ & $2(4)$ & $2(4)$ \\
\hline CG & $32(64)$ & $14(28)$ & $4(8)$ & $0(0)$ & $0(0)$ \\
\hline SCG & $28(56)$ & $16(32)$ & $3(6)$ & $2(4)$ & I (2) \\
\hline PG & $38(76)$ & II (22) & I (2) & $0(0)$ & $0(0)$ \\
\hline \multicolumn{6}{|c|}{ Vomiting } \\
\hline SG & $26(52)$ & II (22) & $7(14)$ & $4(8)$ & $2(4)$ \\
\hline CG & $38(76)$ & $9(18)$ & $3(6)$ & $0(0)$ & $0(0)$ \\
\hline SCG & $35(70)$ & $10(20)$ & $5(10)$ & $0(0)$ & $0(0)$ \\
\hline PG & $40(80)$ & $8(16)$ & $2(4)$ & $0(0)$ & $0(0)$ \\
\hline \multicolumn{6}{|c|}{ Diarrhea } \\
\hline SG & $20(40)$ & $15(30)$ & $8(16)$ & $4(8)$ & $3(6)$ \\
\hline CG & $24(48)$ & $16(32)$ & $5(10)$ & $3(6)$ & $2(4)$ \\
\hline SCG & $22(44)$ & $14(28)$ & $9(18)$ & $4(8)$ & I (2) \\
\hline PG & $32(64)$ & $10(20)$ & $4(8)$ & $3(6)$ & I (2) \\
\hline
\end{tabular}

Notes: Before the experiments, all patients had no side effects. There are significant statistic differences at $P<0.05$.

Abbreviations: SCG, sitagliptin and chitosan oligosaccharide group; CG, chitosan oligosaccharide group; SG, sitagliptin group; PG, placebo group; SD, standard deviation.

CRP was lower in SCG than SG and other groups after 2-day culture $(P<0.05$, Figure 6B). Relative protein level of TNF- $\alpha$ was lower in SCG than SG and other groups after 1 -day culture $(P<0.05$, Figure $6 \mathrm{C})$. In contrast, the relative protein level of adiponectin was higher in SCG than SG and other groups after 1-day culture $(P<0.05$, Figure 6D).

\section{Discussion}

Glycemic control is an important issue for the therapy of T2DM. In the present experiment, the combination therapy of sitagliptin and COS shows better glycemic control efficacy in elderly patients with T2DM when compared with the usage of only one kind of medicine. Combination therapy causes significant decreases in BMI (Figure 2A) and HbA1c $>2.0 \%$ (Figure 2B).

The use of a combined treatment improves glycemic and weight control in most subjects with T2DM. Meanwhile, the levels of $\mathrm{C}$ peptide, $\beta$-cell function index, and adiponectin are also increased. Theoretically, although both groups have similar diabetes prevalence, there are significant statistical differences in adiposity, HOMA-IR and blood pressure, lipid profile, and other biochemical characteristics among the four groups, while SCG shows better therapeutic results than SG. All the changes are beneficial to the therapy of T2DM by using different treatment strategies.

The present findings indicated that combined therapy shows higher efficiency for controlling glucose level of patients in SCG than in SG. The results also suggest that COS can improve therapeutic results of sitagliptin for patients having glycemic levels that are difficult to control. Thus, combination therapy was superior in SCG for the elderly patients with T2DM when compared with the patients from the SG group. One important aspect that should be noted is that all subjects in the SCG group received combined therapy; however, combined therapy involves oral intake of the agents two times a day and reduces fasting and postprandial glucose. COS promotes glycemic control in T2DM subjects with difficulty in controlling the glycemic value. It has complementary functions with sitagliptin in the therapy of T2DM.

Similarly, BMI reduction was also observed in combined therapy (Table 1). On the other hand, HbA1c levels decreased more significantly in SCG than in the SG group compared with levels prior to the trial (Table 1); since this decrease was consistent with the reduction in body weight (Table 1), it indicated that the observed weight reduction is a reliable means to achieve glycemic control effectively. Weight loss occurred continuously in the SCG group that received combined therapy. Meanwhile, better glycemic control and overall system effect were also observed. Considering the key factor of obesity in the pathophysiology of $\mathrm{T} 2 \mathrm{DM},{ }^{33}$ it is necessary to reduce the risk factor by lowering the glucose level.

The combination therapy reduced the concentration of resistin, CRP, and TNF- $\alpha$ when compared with PG (Figure 3, $P<0.05)$. On the other hand, it increased the concentration of 

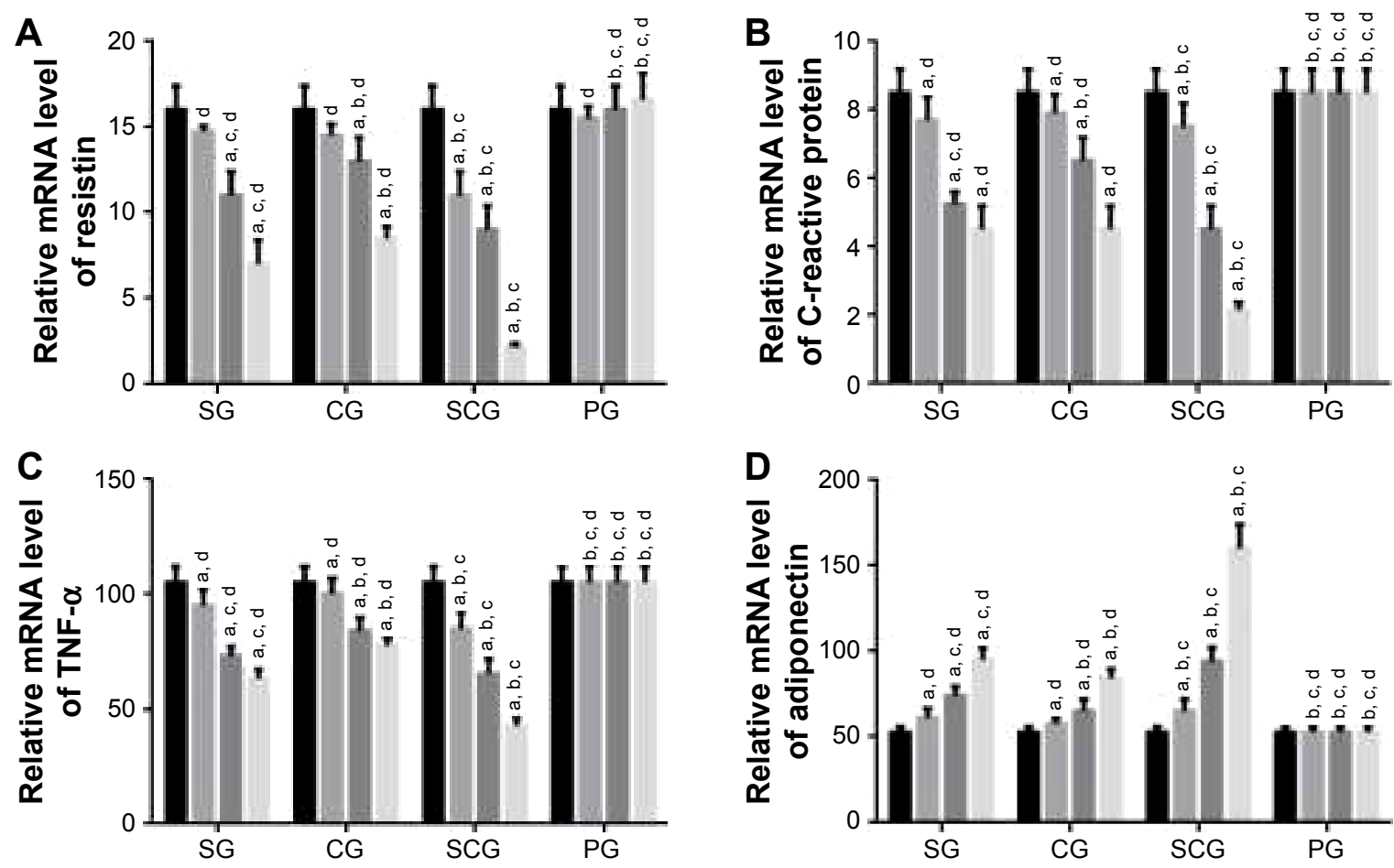

0 day 1 day 2 days $\quad 3$ days

Figure 5 Real-time qPCR analysis of relative mRNA levels of (A) resistin, (B) C-reactive protein, (C) TNF- $\alpha$, and (D) adiponectin between SCG and SG groups in human pancreatic cancer cell lines 3T3-LI and 3T3-F442A.

Note: ${ }^{\mathrm{P}}<0.05$ versus $P G$, ${ }^{b} P<0.05$ versus $S G,{ }^{c} P<0.05$ versus $C G$, and ${ }^{d} P<0.05$ versus $S C G$.

Abbreviations: SCG, sitagliptin and chitosan oligosaccharide group; CG, chitosan oligosaccharide group; SG, sitagliptin group; PG, placebo group; qPCR, quantitative polymerase chain reaction; TNF, tumor necrosis factor.
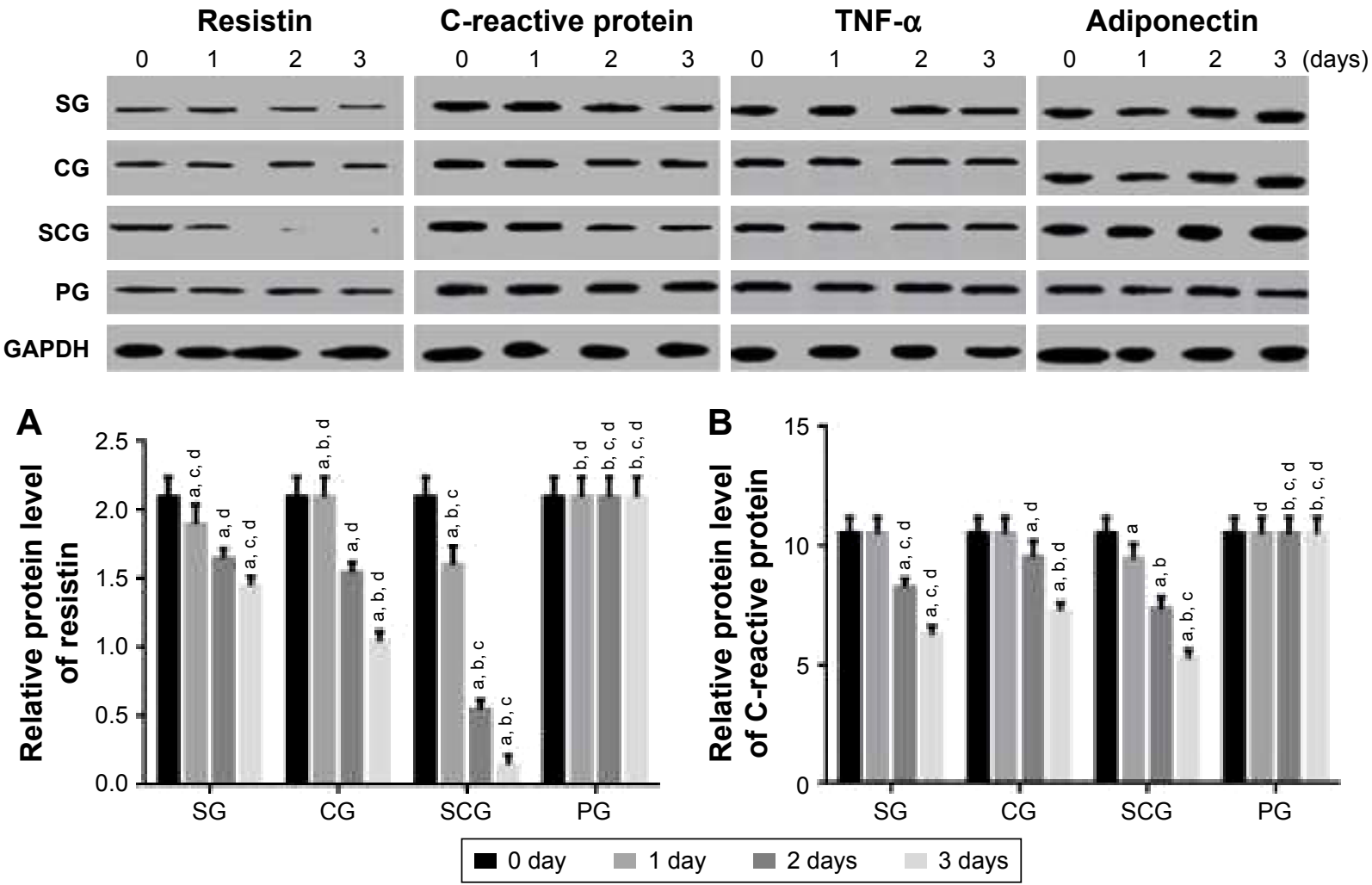

Figure 6 (Continued) 


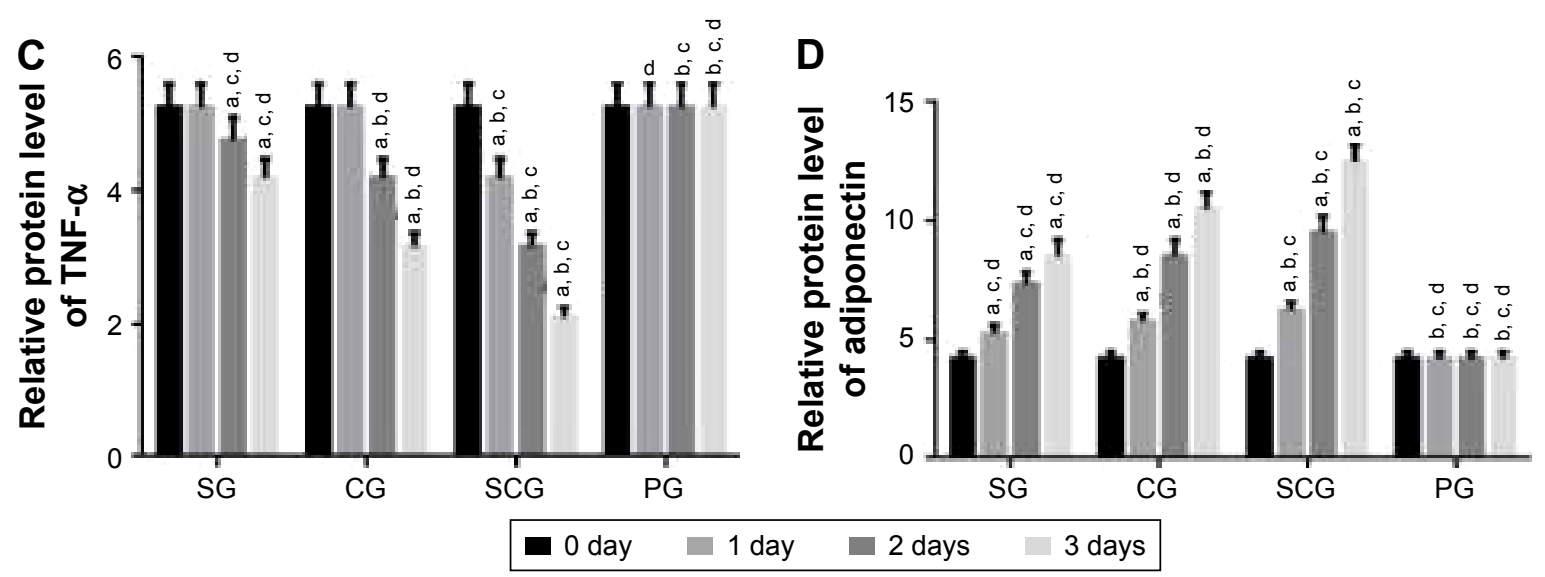

Figure 6 Western blot analysis of relative protein levels of (A) resistin, (B) C-reactive protein, (C) TNF- $\alpha$, and (D) adiponectin between SCG and SG groups in human pancreatic cancer cell lines 3T3-LI and 3T3-F442A.

Note: ${ }^{a} P<0.05$ versus $P G$, ${ }^{b} P<0.05$ versus $S G,{ }^{c} P<0.05$ versus $C G$, and ${ }^{d} P<0.05$ versus $S C G$.

Abbreviations: SCG, sitagliptin and chitosan oligosaccharide group; CG, chitosan oligosaccharide group; SG, sitagliptin group; PG, placebo group; TNF, tumor necrosis factor.

adiponectin and GLP-1 (Figures 3D and 4, $P<0.05$ ). Resistin level is associated with oxidative stress, thromboxanedependent platelet activation and inflammatory activities, and a key determinant of atherothrombosis. Its evaluated level may increase the risk of diabetes. ${ }^{34}$ High-level CRP and TNF- $\alpha$ are also important risk factors of diabetes. . $^{35,36}$ Adiponectin is one kind of adipokines that play a critical role in regulating insulin secretion and glucose and lipid metabolism in diabetic patients. ${ }^{37}$ GLP-1 promotes insulin secretion and demonstrates a protective effect for T2DM patients by controlling oxidative stress generation. ${ }^{38}$ The combination of sitagliptin and COS may ameliorate diabetes by affecting the levels of these molecules.

Comparatively, sitagliptin and COS show similar efficacy for glycemic control in elderly patients with T2DM when compared to patients in the PG group (Table 2). There are no significant differences for the decreases in BMI (Figure 2A) and $\mathrm{HbAlc}>2.0 \%$ (Figure $2 \mathrm{~B}$ ) between $\mathrm{SC}$ and $\mathrm{CG}$ groups. In similar cases, there are no significant differences for CRP and TNF- $\alpha$ either (Table 2). Resistin level is higher in CG than in SG while the adiponectin level is higher in SG than in CG (Table 2, $P<0.05$ ). COS is therefore not superior to sitagliptin in diabetes therapy but it can improve the therapeutic results of sitagliptin.

After long-term use of sitagliptin, most elderly T2DM patients experienced side effects including fatigue, cough, headache, hypoglycemia, loss of consciousness, constipation, nausea, vomiting, and diarrhea. These symptoms were in agreement with previous reports that side effects of fatigue, ${ }^{9}$ cough, ${ }^{9}$ headache, ${ }^{25}$ hypoglycemia, ${ }^{26}$ loss of consciousness, ${ }^{26}$ constipation,,${ }^{27}$ nausea, ${ }^{27}$ vomiting, ${ }^{27}$ and diarrhea ${ }^{28}$ are associated with long-term sitagliptin therapy. COS reduces these side effects and is beneficial to medical therapy of T2DM.

To explore the molecular mechanism for the functions of COS in the therapy of T2DM, human pancreatic cancer cell lines 3T3-L1 and 3T3-F442A were treated with sitagliptin or COS. Results showed that COS reduced the levels of resistin, CRP, and TNF- $\alpha$ and increased the level of adiponectin $(P<0.05$, Figures 5 and 6$)$. Combined with the results from the clinical test, these findings suggest that COS may ameliorate T2DM by affecting the levels of resistin, CRP, and $\mathrm{TNF}-\alpha$, and increasing the level of adiponectin.

\section{Conclusion}

We explored the role of COS in elderly T2MD patients who received sitagliptin. SCG group showed better results than SG and other groups for controlling glycemic values. The combined treatment resulted in a higher increase in the concentration of adiponectin and higher decrease of the concentrations of CRP, resistin, and TNF- $\alpha$ in SCG than in the SG group $(P<0.05)$. This combined treatment showed effective therapeutic results for elderly T2DM patients and should be developed as a potential option for their T2DM therapy.

\section{Disclosure}

The authors report no conflicts of interest in this work.

\section{References}

1. Gilden JL, Gupta A. Non-ICU hospital care of diabetes mellitus in the elderly population. Curr Diab Rep. 2015;15(5):26. 
2. Wild S, Roglic G, Green A, Sicree R, King H. Global prevalence of diabetes: estimates for the year 2000 and projections for 2030. Diabetes Care. 2004;27(5):1047-1053.

3. Bramlage P, Gitt AK, Binz C, Krekler M, Deeg E, Tschope D. Oral antidiabetic treatment in type-2 diabetes in the elderly: balancing the need for glucose control and the risk of hypoglycemia. Cardiovasc Diabetol. 2012;11:122.

4. Bordier L, Buysschaert M, Bauduceau B, et al. Predicting factors of hypoglycaemia in elderly type 2 diabetes patients: contributions of the GERODIAB study. Diabetes Metab. 2015;41(4):301-303.

5. Suresh PS, Srinivas NR, Mullangi R. A concise review of the bioanalytical methods for the quantitation of sitagliptin, an important dipeptidyl peptidase-4 (DPP4) inhibitor, utilized for the characterization of the drug. Biomed Chromatogr. 2016;30(5):749-771.

6. Goldshtein I, Karasik A, Melzer-Cohen C, et al. Urinary albumin excretion with sitagliptin compared to sulfonylurea as add on to metformin in type 2 diabetes patients with albuminuria: a real-world evidence study. J Diabetes Complications. 2016;30(7):1354-1359.

7. Ali SM, Khalifa H, Mostafa DK, El Sharkawy A. Suppression of connective tissue growth factor mediates the renoprotective effect of sitagliptin rather than pioglitazone in type 2 diabetes mellitus. Life Sci. 2016;153:180-187.

8. Shankar RR, Xu L, Golm GT, et al. A comparison of glycaemic effects of sitagliptin and sulfonylureas in elderly patients with type 2 diabetes mellitus. Int J Clin Pract. 2015;69(6):626-631.

9. Baraniuk JN, Jamieson MJ. Rhinorrhea, cough and fatigue in patients taking sitagliptin. Allergy Asthma Clin Immunol. 2010;6(1):8.

10. Sitagliptin + metformin: new combination. Do not use this combination. Sitagliptin provides a slight increase of glucose-lowering effects, but there is a disturbing potential for long-term adverse effects: infections, depression, and cancer. Prescrire Int. 2009;18(101):115.

11. Ngo D-H, Vo T-S, Ngo D-N, et al. Biological effects of chitosan and its derivatives. Food Hydrocoll. 2015;51:200-216.

12. Li X, Shi X, Jin Y, Ding F, Du Y. Controllable antioxidative xylanchitosan Maillard reaction products used for lipid food storage. Carbohydr Polym. 2013;91(1):428-433.

13. Teixeira GQ, Leite Pereira C, Castro F, et al. Anti-inflammatory chitosan/poly- $\gamma$-glutamic acid nanoparticles control inflammation while remodeling extracellular matrix in degenerated intervertebral disc. Acta Biomater. 2016;42:168-179.

14. Karahaliloglu Z, Kilicay E, Denkbas EB. Antibacterial chitosan/silk sericin 3D porous scaffolds as a wound dressing material. Artif Cells Nanomed Biotechnol. Epub 2016 Jul 9.

15. Kerch $\mathrm{G}$. The potential of chitosan and its derivatives in prevention and treatment of age-related diseases. Mar Drugs. 2015;13(4): 2158-2182.

16. Cobrado L, Silva-Dias A, Azevedo MM, Pina-Vaz C, Rodrigues AG. In vivo antibiofilm effect of cerium, chitosan and hamamelitannin against usual agents of catheter-related bloodstream infections. J Antimicrob Chemother. 2013;68(1):126-130.

17. Kim JG, Jo SH, Ha KS, et al. Effect of long-term supplementation of low molecular weight chitosan oligosaccharide (GO2KA1) on fasting blood glucose and $\mathrm{HbA} 1 \mathrm{c}$ in $\mathrm{db} / \mathrm{db}$ mice model and elucidation of mechanism of action. BMC Complement Altern Med. 2014;14:272.

18. Kim HJ, Ahn HY, Kwak JH, et al. The effects of chitosan oligosaccharide (GO2KA1) supplementation on glucose control in subjects with prediabetes. Food Funct. 2014;5(10):2662-2669.

19. Yu SY, Kwon YI, Lee C, Apostolidis E, Kim YC. Antidiabetic effect of chitosan oligosaccharide (GO2KA1) is mediated via inhibition of intestinal alpha-glucosidase and glucose transporters and PPAR. BioFactors. 2017;43(1):90-99.

20. Skwarczynski M, Ghaffar AK, Giddam AK, Batzloff M, Good M, Toth I. Highly immunogenic trimethyl chitosan-based delivery system for intranasal lipopeptide vaccines against group A streptococcus. Curr Drug Deliv. Epub 2016 Jul 21.
21. Yousef M, Pichyangkura R, Soodvilai S, Chatsudthipong V, Muanprasat C. Chitosan oligosaccharide as potential therapy of inflammatory bowel disease: therapeutic efficacy and possible mechanisms of action. Pharmacol Res. 2012;66(1):66-79.

22. Dennhart N, Fukamizo T, Brzezinski R, Lacombe-Harvey ME, Letzel T. Oligosaccharide hydrolysis by chitosanase enzymes monitored by real-time electrospray ionization-mass spectrometry. J Biotechnol. 2008;134(3-4):253-260

23. General Assembly of the World Medical Association. World Medical Association Declaration of Helsinki: ethical principles for medical research involving human subjects. J Am Coll Dent. 2014;81(3): 14-18.

24. Engelgau MM, Thompson TJ, Herman WH, et al. Comparison of fasting and 2-hour glucose and HbA1c levels for diagnosing diabetes. Diagnostic criteria and performance revisited. Diabetes Care. 1997; 20(5):785-791.

25. Arjona Ferreira JC, Corry D, Mogensen CE, et al. Efficacy and safety of sitagliptin in patients with type 2 diabetes and ESRD receiving dialysis: a 54-week randomized trial. Am J Kidney Dis. 2013;61(4):579-587.

26. Sakamoto Y, Oyama J, Ikeda H, et al. Effects of sitagliptin beyond glycemic control: focus on quality of life. Cardiovasc Diabetol. 2013;12:35.

27. Wang T, Gou Z, Wang F, Ma M, Zhai SD. Comparison of GLP-1 analogues versus sitagliptin in the management of type 2 diabetes: systematic review and meta-analysis of head-to-head studies. PLoS One. 2014;9(8):e103798.

28. Zhao Q, Hong D, Zheng D, Xiao Y, Wu B. Risk of diarrhea in patients with type 2 diabetes mellitus treated with sitagliptin: a metaanalysis of 30 randomized clinical trials. Drug Des Devel Ther. 2014;8: 2283-2294.

29. Freeman DJ, Norrie J, Caslake MJ, et al. C-reactive protein is an independent predictor of risk for the development of diabetes in the West of Scotland Coronary Prevention Study. Diabetes. 2002;51(5): $1596-1600$

30. Xu H, Uysal KT, Becherer JD, Arner P, Hotamisligil GS. Altered tumor necrosis factor-alpha (TNF-alpha) processing in adipocytes and increased expression of transmembrane TNF-alpha in obesity. Diabetes. 2002;51(6):1876-1883.

31. Yamamoto H, Maeda K, Uji Y, et al. Association between reduction of plasma adiponectin levels and risk of bacterial infection after gastric cancer surgery. PLoS One. 2013;8(3):e56129.

32. Shehzad A, Iqbal W, Shehzad O, Lee YS. Adiponectin: regulation of its production and its role in human diseases. Hormones. 2012;11(1): $8-20$.

33. Mohammadzadeh G, Zarghami N. Hypoadiponectinemia in obese subjects with type II diabetes: a close association with central obesity indices. J Res Med Sci. 2011;16(6):713-723.

34. Santilli F, Liani R, Di Fulvio P, et al. Increased circulating resistin is associated with insulin resistance, oxidative stress and platelet activation in type 2 diabetes mellitus. Thromb Haemost. 2016;116(6):1089-1099.

35. Korovkin VS. Реакция C-реактивного белка у пациентов с туберкулезом и сахарным диабетом [The C-reactive protein reaction in patients with tuberculosis and diabetes mellitus]. Probl Tuberk. 1968;46(7):90-91. Russian.

36. Ziamajidi N, Nasiri A, Abbasalipourkabir R, Sadeghi Moheb S. Effects of garlic extract on TNF-alpha expression and oxidative stress status in the kidneys of rats with STZ + nicotinamide-induced diabetes. Pharm Biol. 2017;55(1):526-531.

37. Pawlik A, Teler J, Maciejewska A, Sawczuk M, Safranow K, Dziedziejko V. Adiponectin and leptin gene polymorphisms in women with gestational diabetes mellitus. J Assist Reprod Genet. 2017;34(4): 511-516.

38. Ceriello A, Esposito K, Testa R, Bonfigli AR, Marra M, Giugliano D. The possible protective role of glucagon-like peptide 1 on endothelium during the meal and evidence for an "endothelial resistance" to glucagonlike peptide 1 in diabetes. Diabetes Care. 2011;34(3):697-702. 


\section{Publish your work in this journal}

Therapeutics and Clinical Risk Management is an international, peerreviewed journal of clinical therapeutics and risk management, focusing on concise rapid reporting of clinical studies in all therapeutic areas, outcomes, safety, and programs for the effective, safe, and sustained use of medicines. This journal is indexed on PubMed Central, CAS,

EMBase, Scopus and the Elsevier Bibliographic databases. The manuscript management system is completely online and includes a very quick and fair peer-review system, which is all easy to use. Visit http://www.dovepress.com/testimonials.php to read real quotes from published authors.

Submit your manuscript here: http://www.dovepress.com/therapeutics-and-clinical-risk-management-journal 